\title{
Aerothermodynamic Design of the Mars Science Laboratory Backshell and Parachute Cone
}

\author{
Karl T. Edquist* and Artem A. Dyakonov ${ }^{\dagger}$ \\ NASA Langley Research Center, Hampton, Virginia, 23681 \\ Michael J. Wright ${ }^{\ddagger}$ and Chun Y. Tang ${ }^{\S}$ \\ NASA Ames Research Center, Moffett Field, California, 94035
}

\begin{abstract}
Aerothermodynamic design environments are presented for the Mars Science Laboratory entry capsule backshell and parachute cone. The design conditions are based on Navier-Stokes flowfield simulations on shallow (maximum total heat load) and steep (maximum heat flux) design entry trajectories from a 2009 launch. Transient interference effects from reaction control system thruster plumes were included in the design environments when necessary. The limiting backshell design heating conditions of $6.3 \mathrm{~W} / \mathrm{cm}^{2}$ for heat flux and $377 \mathrm{~J} / \mathrm{cm}^{2}$ for total heat load are not influenced by thruster firings. Similarly, the thrusters do not affect the parachute cover lid design environments $\left(13 \mathrm{~W} / \mathrm{cm}^{2}\right.$ and 499 $\left.J / \mathrm{cm}^{2}\right)$. If thruster jet firings occur near peak dynamic pressure, they will augment the design environments at the interface between the backshell and parachute cone $\left(7 \mathrm{~W} / \mathrm{cm}^{2}\right.$ and $\left.174 \mathrm{~J} / \mathrm{cm}^{2}\right)$. Localized heat fluxes are higher near the thruster fairing during jet firings, but these areas did not require additional thermal protection material. Finally, heating bump factors were developed for antenna radomes on the parachute cone.
\end{abstract}

\section{Nomenclature}

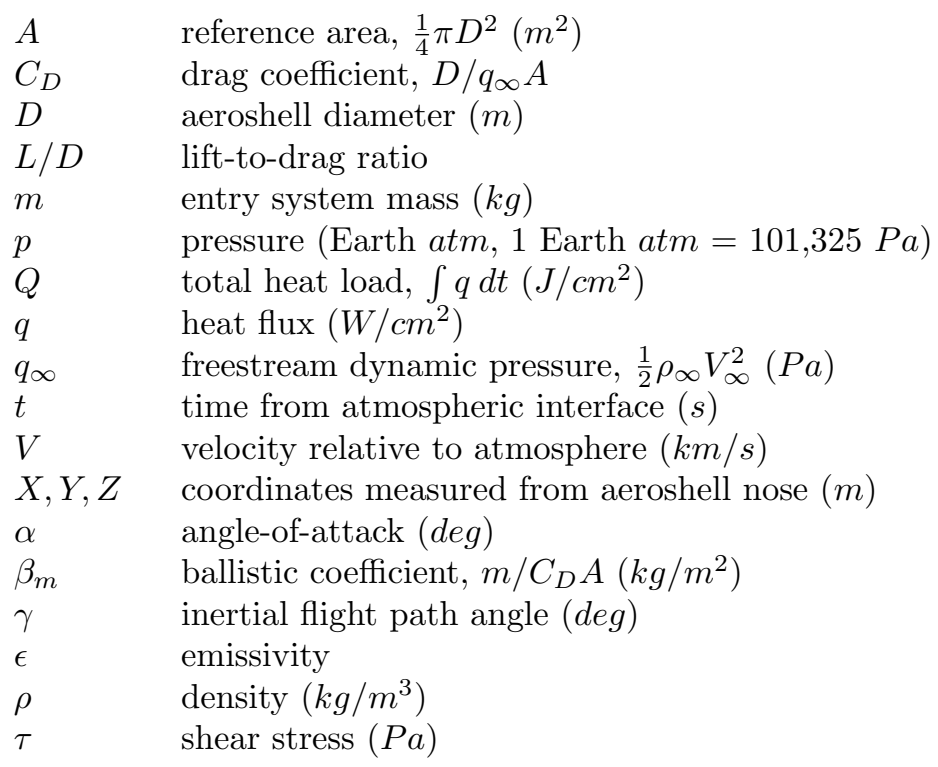

${ }^{*}$ Aerospace Engineer, Atmospheric Flight and Entry Systems Branch, Mail Stop 489, Senior Member, Karl.T.Edquist@nasa.gov.

${ }^{\dagger}$ Aerospace Engineer, Atmospheric Flight and Entry Systems Branch, Mail Stop 489, Member.

${ }^{\ddagger}$ Senior Research Scientist, Reacting Flow Environments Branch, Mail Stop 230-2, Associate Fellow.

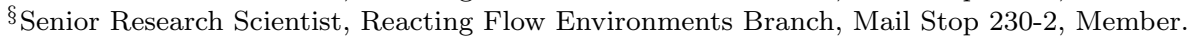




$\begin{array}{ll}\text { AWG } & \text { Aeroheating Working Group } \\ \text { BIP } & \text { Backshell Interface Plate } \\ \text { CFD } & \text { Computational Fluid Dynamics } \\ \text { DPLR } & \text { Data Parallel Line Relaxation } \\ \text { LAURA } & \text { Langley Aerothermodynamic Upwind Relaxation Algorithm } \\ \text { MSL } & \text { Mars Science Laboratory } \\ \text { PCC } & \text { Parachute Closeout Cone } \\ \text { PICA } & \text { Phenolic Impregnated Carbon Ablator } \\ \text { RCS } & \text { Reaction Control System } \\ \text { SST } & \text { Shear Stress Transport } \\ \text { TPS } & \text { Thermal Protection System } \\ & \\ \text { Subscripts } & \\ & \\ \text { trim } & \text { aerodynamic trim condition } \\ w & \text { surface condition } \\ \infty & \text { freestream condition }\end{array}$

\section{Introduction}

NaSA's Mars Science Laboratory (MSL) entry system ${ }^{1}$ will deliver a large rover $(>900 \mathrm{~kg}$ ) to the surface of Mars within a distance of $10 \mathrm{~km}$ from the landing target. The entry system will land the rover using an aeroshell and parachute architecture that has successfully delivered payloads on Mars starting with Viking ${ }^{2}$ and continuing with Pathfinder, ${ }^{3}$ the Mars Exploration Rovers, ${ }^{4}$ and Phoenix. ${ }^{5}$ Prior to supersonic parachute deployment, the MSL entry capsule will fly with a hypersonic lift-to-drag ratio $(L / D)$ of 0.24 at a trim angle-of-attack of $16 \mathrm{deg}$ using active guidance and reaction control system (RCS) thruster to control lift vector direction. Ballast mass will be used to give the capsule the necessary radial center-of-gravity offset for the desired $L / D$. MSL launch, until recently scheduled for the Fall of 2009, has been delayed until late 2011 with landing in Summer of 2012.

The interaction between the MSL aeroshell and Martian atmosphere will dissipate more than 99\% of the entry system's initial kinetic energy, mostly in the form of heat. MSL's thermal protection system ${ }^{6-?}$ (TPS) will keep the aeroshell interior from these extreme environments. The objective of this paper is to summarize the MSL aerothermodynamic design process and conditions needed to support TPS development ${ }^{6}$ for the backshell, Backshell Interface Plate (BIP), and Parachute Closeout Cone (PCC). A companion paper ${ }^{7}$ covers design environments for the entry capsule heatshield. Previous computational ${ }^{8,9}$ and experimental ${ }^{10-12}$ aerothermodynamics analyses have been performed for various MSL aeroshell configurations and design trajectories. This paper covers the analysis used to support flight TPS hardware development for the original 2009 launch opportunity. Analysis is pending for the new 2011 launch date.

\section{A. Aeroshell and Thermal Protection System}

The MSL aeroshell is a 4.5-meter diameter 70-degree half-angle sphere-cone forebody with a triconic afterbody (Figure 1a). All previous major NASA Mars capsules used the same forebody shape and LockheedMartin's SLA-561V ${ }^{13}$ ablative heatshield TPS material. The unprecedented magnitude of the MSL heatshield environments led to SLA-561V test anomalies ${ }^{14}$ and prompted a switch to the Phenolic Impregnated Carbon Ablator $^{15}$ (PICA). Similarly, MSL requirements necessitated new solutions for the backshell and PCC TPS materials compared to past missions. The same SLA-561V material used for previous heatshields will be used for MSL's backshell, primarily to withstand the adverse interference effects of RCS thruster plumes. The material is a mixture of ground cork, silica, and phenolic in a silicone binder that is hand-packed into a phenolic honeycomb. The SLA-561V backshell thickness $(0.5 \mathrm{in})$ was chosen prior to completion of the 
aerothermodynamic and TPS analyses to erduce risks posed by RCS thrusters. Thus, the backshell TPS analysis focused on proving the adequacy of 0.5 in rather than deriving a minimum required thickness. ${ }^{6}$ No recession is expected for the SLA- $561 \mathrm{~V}$ in response to the environments presented here. A less robust spray-on version of SLA-561 has been used on previous backshells whose environments were less severe than they will be for MSL and were not influenced by large RCS thrusters.

ITT-Aerotherm's Acusil II is a silicone foam material that was chosen to protect the BIP and PCC because it permits radio frequency transmission and can be molded to cover complex surface geometries; the material is frequently used for tactical missile applications. There are multiple antennas inside the PCC that must be able to transmit signals before the PCC is ejected at supersonic parachute deployment. Variable Acusil II thicknesses were tailored to the design environments presented here in order to maintain acceptable bondline temperatures for various elements. ${ }^{6}$ Acusil II does not ablate for heat fluxes below $100 \mathrm{~W} / \mathrm{cm}^{2}$, which is well above what MSL will experience. Manufacturing of the MSL aeroshell, including the backshell and PCC, has already been completed in anticipation of the original 2009 launch.

Some features on the backshell and PCC required special consideration in the design environments definition (Figure 1b). Some of the components, such as access doors, are nearly flush with the surrounding surface and will not introduce significant adverse effects on the local heating. Consequently, the smooth surface environments and tailored ground tests were sufficient to support TPS development. Other features, such as antenna radomes on the PCC (TLGA and PLGA), required tailored aerothermodynamic analysis because they are expected to augment heating levels above the surrounding magnitudes. The Acusil II thicknesses on the radomes was optimized to satisfy thermal requirements and permit radio frequency transmission. ${ }^{6}$ Similarly, the BIP TPS thickness was optimized to satisfy both thermal and mechanical requirements; large parachute deployment structural loads must be supported at the BIP location.

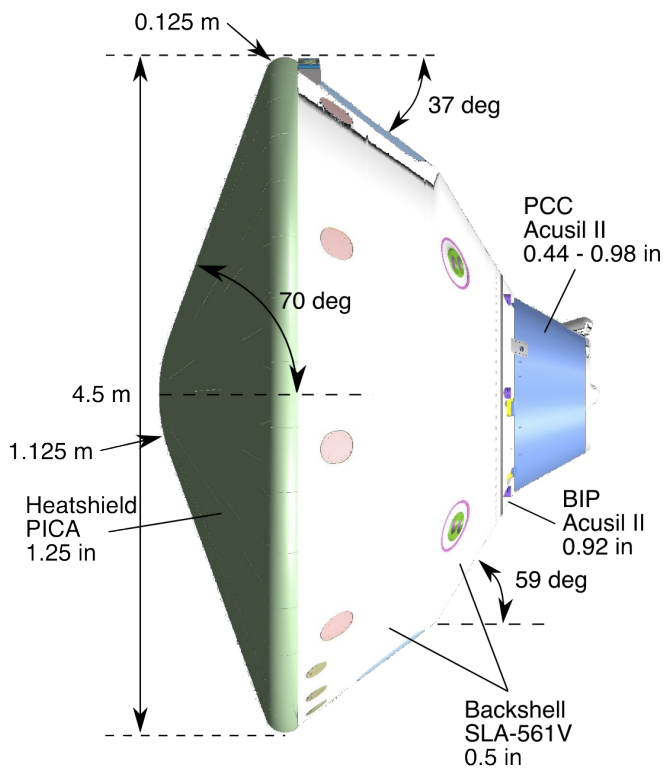

(a) Geometry and Thermal Protection System

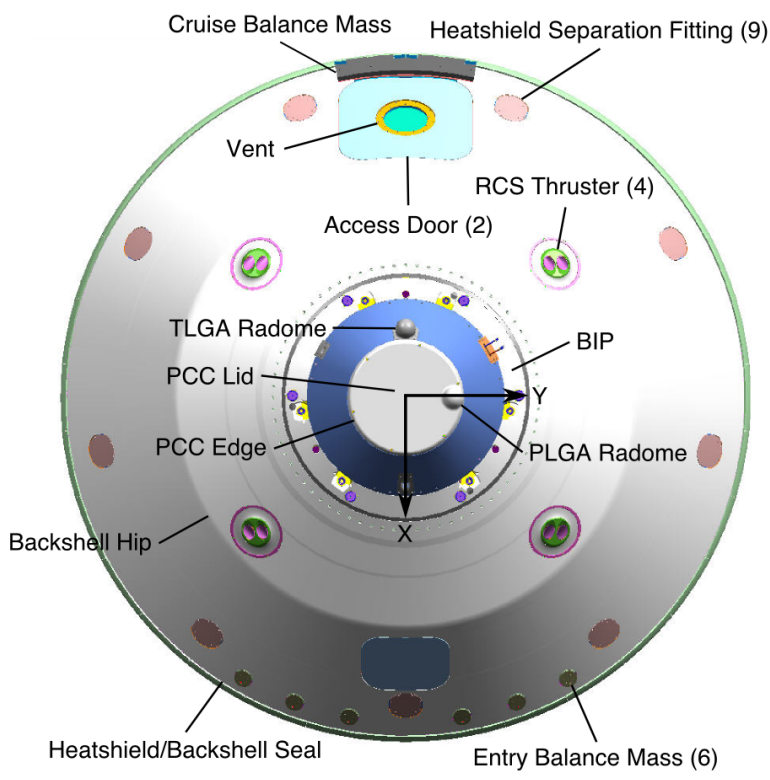

(b) Backshell/PCC Features

Figure 1. MSL Aeroshell

Significant effort was spent to model the interference effects of RCS thruster plumes on the afterbody flowfield and surface conditions. The MSL entry guidance algorithm will command multiple firings of the thrusters (4 pairs) to orient the capsule's lift vector direction and maintain acceptable attitude rates. It is possible that the cumulative on time for any thruster could be several seconds during the exo-atmospheric and atmospheric phases of the entry sequence. Prior to atmospheric interface, the thruster plumes will expand into near vacuum and directly deposit hot gases onto the surface. In the continuum regime, the plumes will interfere with a supersonic external flowfield, causing further impingement and heat fluxes much larger 
than the thruster-off heating. In addition, each thruster location has a pair of nozzles whose exit plumes will interfere with one another during simultaneous firings, further exacerbating the situation. Multiple MSL RCS configurations (thruster location and pointing direction) have been analyzed computationally; the final configuration shown in Figure 1 was chosen to avoid as much as possible adverse thruster plume effects on capsule aerodynamics ${ }^{16,17}$ and aerothermodynamics. Also, the decision to use SLA-561V on the backshell was made in response to concerns about the transient effects of RCS thruster firings on local heating. The Viking entry capsules used RCS jets during entry, ${ }^{2}$ but they were relatively small and were needed only for attitude rate damping, not banking maneuvers like MSL will perform. The Phoenix RCS was essentially turned off ${ }^{18}$ because analysis showed that the intended thruster torques would be countered by plume interference effects. MSL presented the first opportunity for extensive CFD modeling of RCS thruster plumes on a Mars entry capsule; no ground testing was done to support the computational aerothermal analysis.

\section{B. Aerothermodynamic Design Trajectories}

Multiple design trajectories were used during the MSL project to define aerothermodynamic conditions for the backshell and PCC. For the original 2009 launch date, the 08-TPS-01a and 08-TPS-02 trajectories were designated for aerothermodynamic and TPS design (Figure 2 and Table 1). The trajectories differ only in inertial entry flight path angle $(\gamma)$. The shallow 08-TPS-01a trajectory (entry $\gamma=-14 \mathrm{deg}$ ) has a longer time of flight and the highest integrated total heat load, which typically requires the largest TPS thickness. The steep 08TPS-02 trajectory (entry $\gamma=-15.5 \mathrm{deg}$ ) gives the peak instantaneous heat flux for material selection and ground test design. The capsule will generate enough lift to achieve nearly horizontal flight leading up to parachute deployment (between 1 and 2 $\mathrm{km} / \mathrm{s}$ ). Initial PCC TPS sizing analysis was based on an earlier design trajectory (06-05) that is similar to 08-TPS-02, but with a higher entry velocity $(5.93$ $\mathrm{km} / \mathrm{s}$ ) and lower ballistic coefficient $\left(126 \mathrm{~kg} / \mathrm{m}^{2}\right)$. The Acusil II thicknesses derived for the 06-05 trajectory have since been shown to be adequate for the new design trajectories.

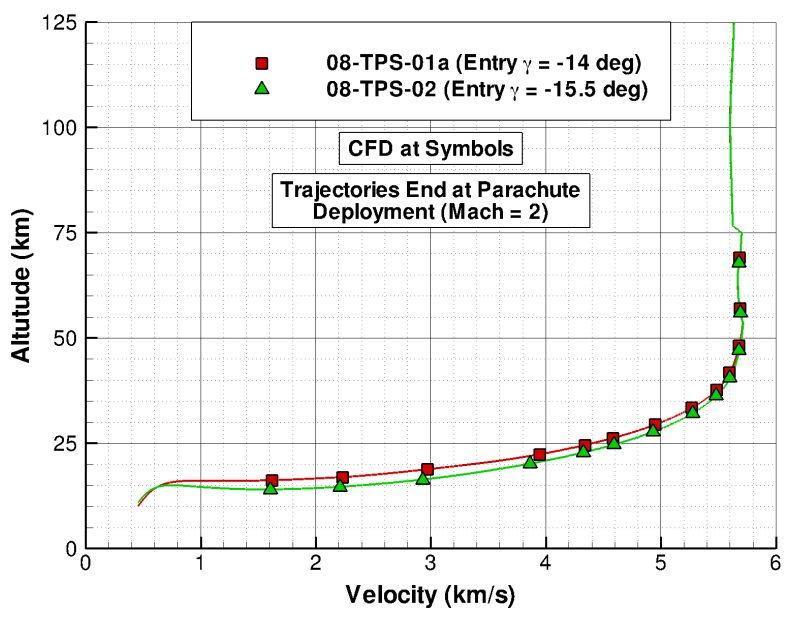

Figure 2. Aerothermodynamic Design Trajectories for the 2009 Launch Opportunity

Table 1. Aerothermodynamic Design Trajectories for the 2009 Launch Opportunity

\begin{tabular}{r|c} 
& 08-TPS-01a $/$ 08-TPS-02 \\
\hline \hline Launch Date & $09 / 20 / 09$ \\
Arrival Date & $07 / 20 / 10$ \\
Entry Mass $(\mathrm{kg})$ & 3380 \\
Entry $V_{\infty}(\mathrm{km} / \mathrm{s})$ & 5.63 \\
Entry $\gamma(\mathrm{deg})$ & $-14 /-15.5$ \\
Time at Parachute Deployment $(\mathrm{s})$ & $280 / 249$
\end{tabular}




\section{MSL Compared to Previous Missions}

Figure 3 and Table 2 compare the MSL capsule and design trajectory characteristics to past successful Mars missions. A few key characteristics make MSL a much more aggressive atmospheric entry than has been previously attempted. First, MSL is much larger and heavier than any of the past entry capsules. MSL's high ballistic coefficient leads to higher aerothermal and structural loads since velocity is maintained deeper into the atmosphere. The MSL rover mass alone $(850 \mathrm{~kg}$ for the design trajectories, $>900 \mathrm{~kg}$ for the flight hardware) is similar to the total entry system masses for Viking and the Mars Exploration Rovers (MER). MSL's landing mass includes the Sky Crane ${ }^{1}$ descent stage that eventually reaches ground after releasing the rover. MSL's comparatively high angle-of-attack will expose MSL's backshell and PCC to attached flow and shear layer re-impingement, both of which were less

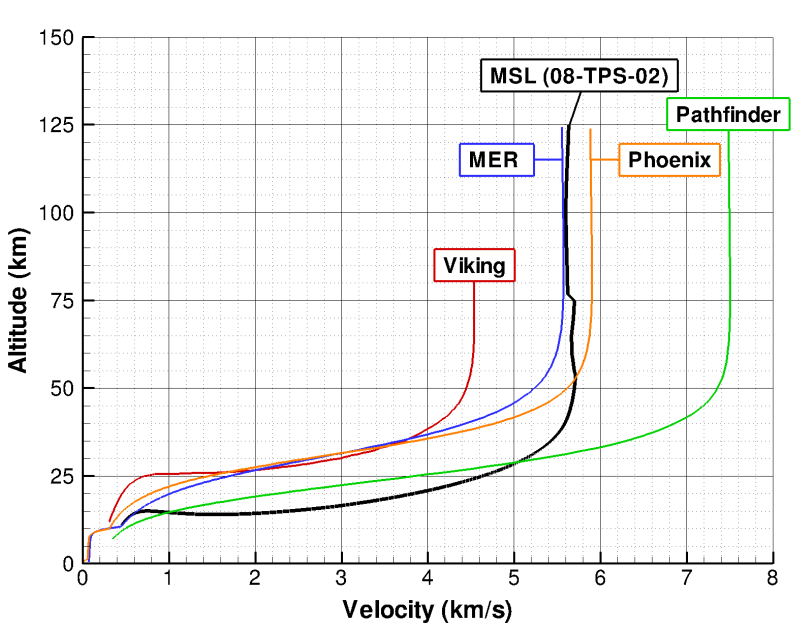

Figure 3. Mars Entry Trajectory Comparison likely for previous capsules at lower trim angles. Finally, MSL's large RCS thrusters prompted the use the SLA-561V material on the backshell. SLA-561V has previously been used only as a heatshield material for Mars entry capsules in worse conditions than MSL's backshell will see.

Table 2. Mars Aeroshell and Entry Trajectory Comparison

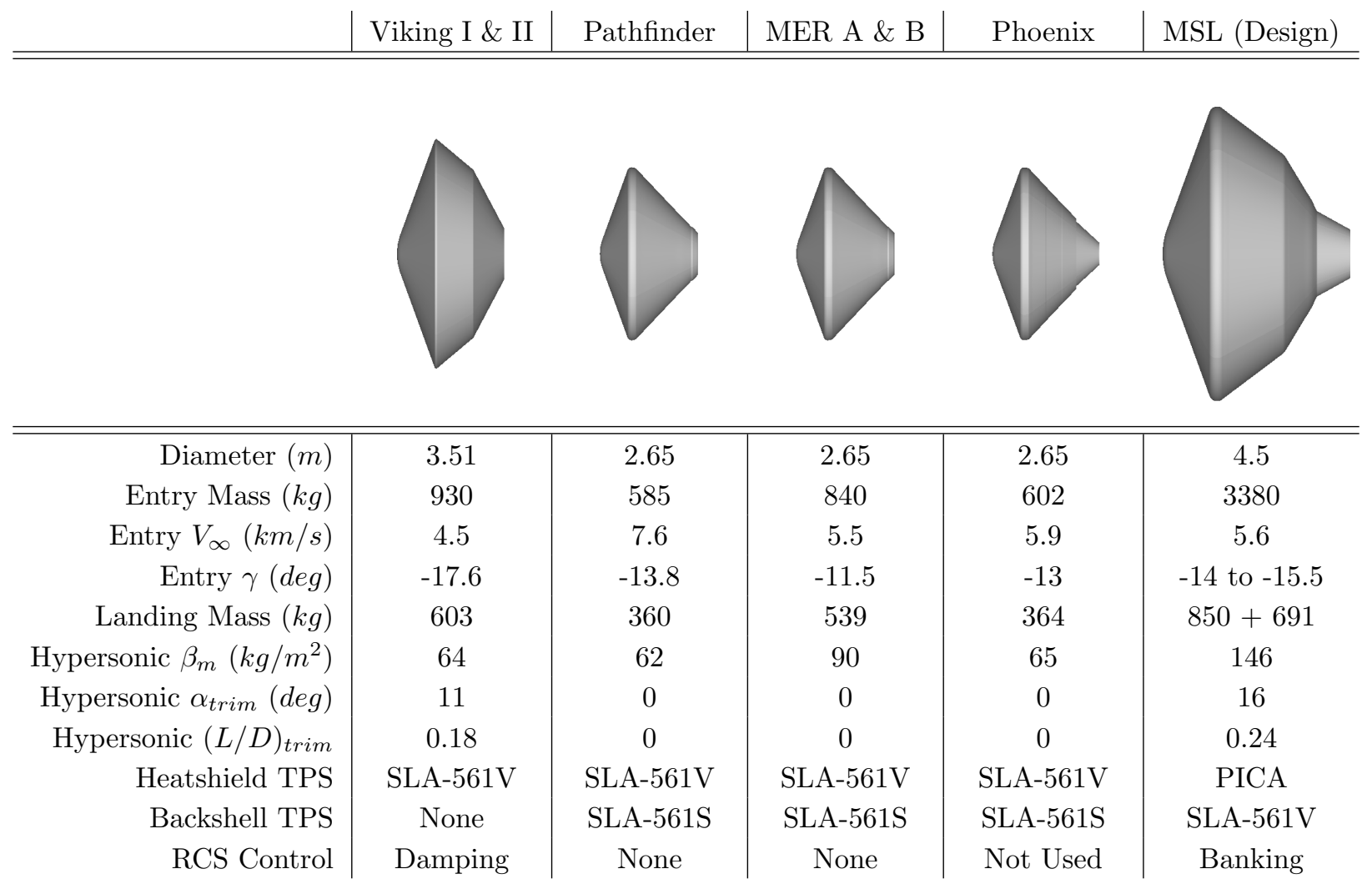




\section{Computational Models}

Ground-based test facilities are unable to reproduce the high-temperature non-equilibrium flowfield conditions that will envelope the MSL aeroshell. Consequently, MSL aerothermodynamic design was based on Navier-Stokes flowfield predictions using established CFD models and large uncertainties. Many challenges ${ }^{19}$ exist when calculating the aerothermodynamic environments for a hypersonic entry capsule. High temperatures generated behind the bow shock lead to chemical and thermal non-equilibrium conditions that require models whose validity at Mars flight conditions often cannot be verified. The challenges are increased for calculation of a blunt body wake flowfield such as the one MSL's aeroshell will generate. Using steady-state CFD models for a flowfield which is transient and possibly turbulent pushes the envelope of computational capabilities. The addition of RCS thruster plume interference effects adds more complexity to an already complicated flowfield. For MSL, conservative assumptions and uncertainties in conjunction with established CFD codes were used to define the design aerothermal environments. In addition, much of the TPS risk was eliminated by choosing a material (SLA-561V) previously shown to be capable of withstanding heatshield environments more severe than MSL's backshell will experience.

The MSL aerothermodynamic environments are based on the Langley Aerothermodynamic Upwind Relaxation Algorithm ${ }^{20}$ (LAURA) and Data Parallel Line Relaxation ${ }^{21}$ (DPLR) Navier-Stokes codes. Both codes have been used for previous Mars and Earth entry capsule flowfield predictions, including Pathfinder, ${ }^{22}$ Phoenix ${ }^{23}$ and Genesis Sample Return Capsule. ${ }^{24,25}$ LAURA is being used ${ }^{16}$ to predict MSL's aerodynamic characteristics in the hypersonic and supersonic continuum flow regimes, including RCS interference effects. ${ }^{17}$ For MSL's heatshield, turbulent solutions were obtained based on the expectation of turbulent transition in flight. No attempt was made to predict turbulent transition on the afterbody due to complex mechanisms that exist for massively separated flowfields. Some DPLR solutions were run with the Shear Stress Transport ${ }^{26}$ (SST) two-equation turbulence model for an assessment of heating bump factors over laminar conditions. The effects of turbulence were otherwise covered by using large uncertainties on laminar heating predictions. Both codes were executed using the conservative super-catalytic boundary condition, which gives the maximum surface chemistry contribution to heating. The model assumptions were as follows:

- Laminar boundary layer (DPLR SST model used to estimate turbulent effects)

- Chemical non-equilibrium $\left(\mathrm{CO}_{2}, \mathrm{CO}, \mathrm{N}_{2}, \mathrm{O}_{2}, \mathrm{NO}, \mathrm{C}, \mathrm{N}, \mathrm{O}, 0.97\right.$ and 0.03 freestream mass fractions for $\mathrm{CO}_{2}$ and $\mathrm{N}_{2}$, respectively)

- Thermal non-equilibrium (translational and vibrational temperatures)

- Radiative-equilibrium wall: $q_{w}=\epsilon \sigma T_{w}^{4}\left(\epsilon=0.89, \sigma=5.67 \times 10^{-8} W /\left(m^{2}-K^{4}\right)\right)$

- Super-catalytic wall: recombination of $\mathrm{CO}_{2}$ and $\mathrm{N}_{2}$ to freestream mass fractions

\section{Results}

The following sections summarize the results of applying the process in Figure 4 to define MSL aerothermodynamic design environments. Given freestream conditions along the design trajectories, CFD solutions were obtained using the model assumptions stated previously. Uncertainties were added to give the design environments for multiple backshell and PCC locations for the 08-TPS-01a (maximum total heat load) and 08-TPS-02 (maximum heat flux, shear stress, and pressure) entry trajectories. Pressure was needed for the TPS analysis, but the magnitudes are small and do not significantly affect required TPS thickness. Similarly, the shear stresses are well within material capabilities.

MSL aeroshell and TPS development was a joint effort between NASA Langley and Ames Research Centers (aerothermodynamic analysis, TPS modeling and testing), NASA Jet Propulsion Laboratory (JPL, project management, PCC development), Lockheed Martin Astronautics (aeroshell development, SLA-561V manufacturer), Fiber Materials Incorporated (FMI, PICA manufacturer), and ITT-Aerotherm (Acusil II manufacturer). The aerothermodynamics analyses that supported the backshell and PCC TPS designs was overseen by the MSL Aeroheating Working Group (AWG) consisting of members from NASA, JPL, 


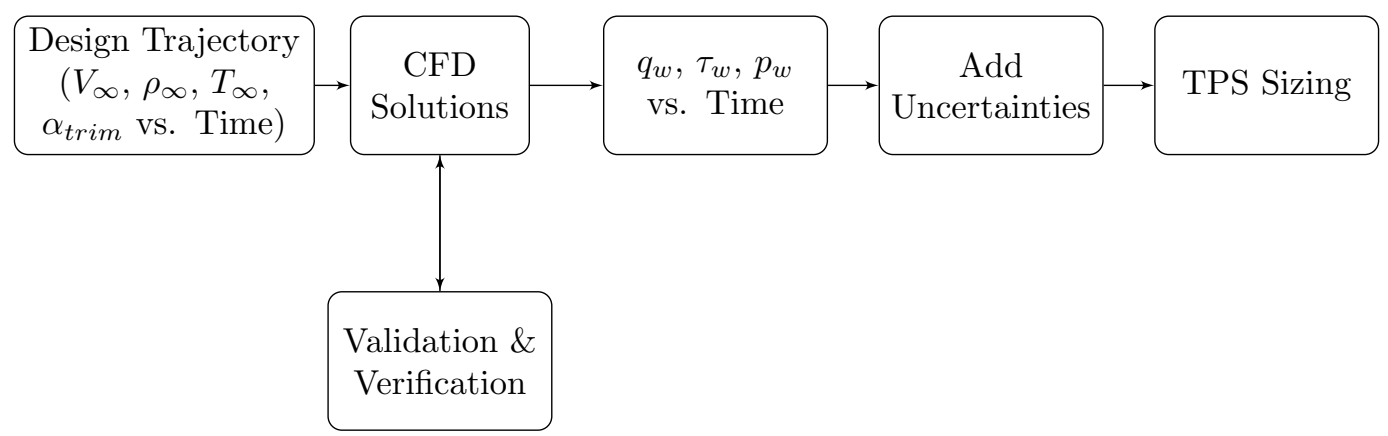

Figure 4. Aerothermodynamic Design Process

and Lockheed Martin. The AWG served as the venue for discussing the state of the aerothermal design environments, interpreting test results, and proposing additional testing and analysis. The aerothermal design process and results were reviewed by project management and subject matter experts, both in detailed and system-level project reviews. The data to follow were used to verify thermal performance for fixed (backshell) and derived (BIP, PCC) TPS thicknesses for the 2009 launch opportunity.

\section{A. Afterbody Flowfield (No RCS Thruster Plume Effects)}

Figure 5 shows a laminar LAURA solution at peak dynamic pressure on the 08-TPS-02 trajectory with RCS thrusters off. At a $16 \mathrm{deg}$ angle-of-attack, the heatshield stagnation point moves off the spherical nosecap and onto the windside flank. The relatively high angle-of-attack causes attached flow on the first windside backshell cone and part of the second cone, followed by shear layer re-impingement on the BIP and PCC sidewall. The areas with attached and impinging flow will see elevated heat flux (Figure 5b). Previous Mars entry capsules that flew at lower angles-of-attack most likely had fully separated wake flowfields that were inherently more difficult to predict, but whose heating environments were generally less severe. The prediction of attached flow heating for MSL was fairly straightforward because the flow is more likely to be steady and grid quality requirements are not as stringent as they are for separated flowfields. Steady-state Navier-Stokes methods are less applicable on the MSL leeside where the flow is separated and unsteady, but the aerothermodynamic environments are less severe than they are on the windside (Figure 5b). Thus, more confidence is placed on the CFD heating predictions on the windside where the attached flow environments are more stressful for the TPS. Nevertheless, large uncertainties were included in the design conditions and SLA-561V was chosen to mitigate concerns about interference effects from RCS thruster plumes.

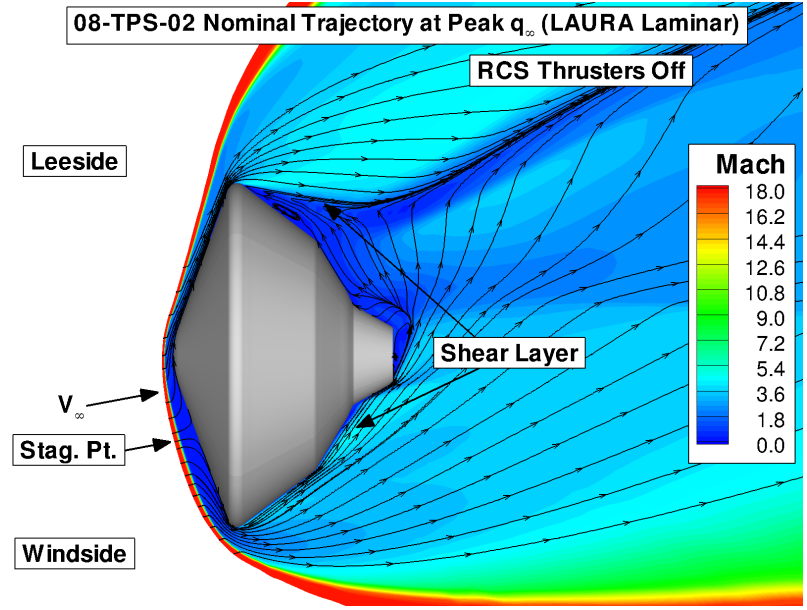

(a) Symmetry Plane Mach Number and Streamlines

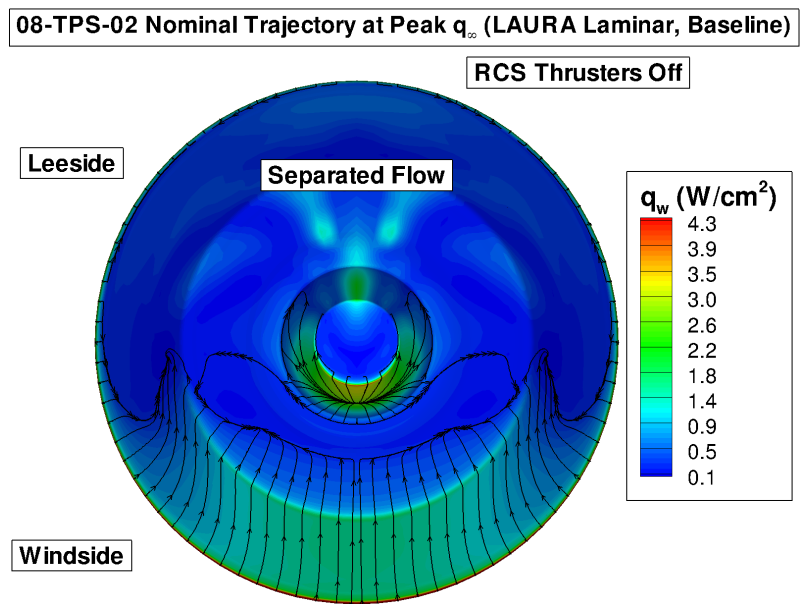

(b) Afterbody Heat Flux (No Uncertainties) and Streamlines

Figure 5. LAURA Solution at Peak Dynamic Pressure on the 08-TPS-02 Trajectory 


\section{B. CFD Code Comparison (No RCS Thruster Plume Effects)}

Very little Mars flight data exist that can help validate LAURA and DPLR backshell heating computations at Mars flight conditions. Both Viking ${ }^{27}$ and Pathfinder ${ }^{28}$ measured backshell temperatures at a limited number of locations. An attempt ${ }^{29}$ was made previously to compare CFD-based heat flux to the Viking data at two discrete locations. Time-averaged laminar LAURA and DPLR super-catalytic heating was up to $80 \%$ below heat flux derived from the flight temperature data. However, the results were somewhat inconclusive because the two flight measurement locations were in a separated unsteady flowfield, a condition which is poorly modeled by Reynolds-averaged Navier-Stokes codes such LAURA and DPLR.

Given the scarcity of Mars flight data, CFD code comparison was the next best option to verify MSL heating predictions. The entry trajectory (07-25) that was used for this exercise is analogous to 08-TPS02 , but with a $5.8 \mathrm{~km} / \mathrm{s}$ entry velocity instead of 5.9. Figure 6 shows a comparison of baseline LAURA (laminar) and DPLR (laminar and SST) symmetry plane heat flux (at peak dynamic pressure) and total heat load on the 07-25 trajectory. No uncertainties or RCS thruster effects are included in these results. Peak dynamic pressure is when backshell, BIP, and PCC heating levels are at or near their peaks. Three locations on the windside $(X>0)$ have local heating maxima: the Heatshield/Backshell Seal at the rear shoulder tangency point $(X=2.2 \mathrm{~m})$, the Backshell Hip $(X=1.5 \mathrm{~m})$, and the PCC Edge $(X=0.4 \mathrm{~m})$. Under laminar conditions, the DPLR heat flux is higher than LAURA on the first windside cone, but the code predictions are similar at the Backshell Hip and windside PCC Edge. The same can be said for the total heat load predictions in Figure $6 \mathrm{~b}$. The discrepancies between laminar predictions on the windside are considered to be within normal modeling uncertainties and do not warrant any special corrections in the design environments. Leeside backshell environments are highly unsteady and do not exceed the windside conditions.

DPLR SST results are also shown to indicate how turbulence could augment afterbody heating. The SST model is a two-equation model that is more appropriate for afterbody flowfields than algebraic turbulence models. The SST heat flux on the windside Backshell Hip and PCC Edge are approximately twice the DPLR laminar levels, but very little augmentation exists at the Heatshield/Backshell Seal. The design heating environments include a large uncertainty on top of laminar heating predictions that more than covers the laminar code discrepancies and turbulent augmentation shown in Figure 6.

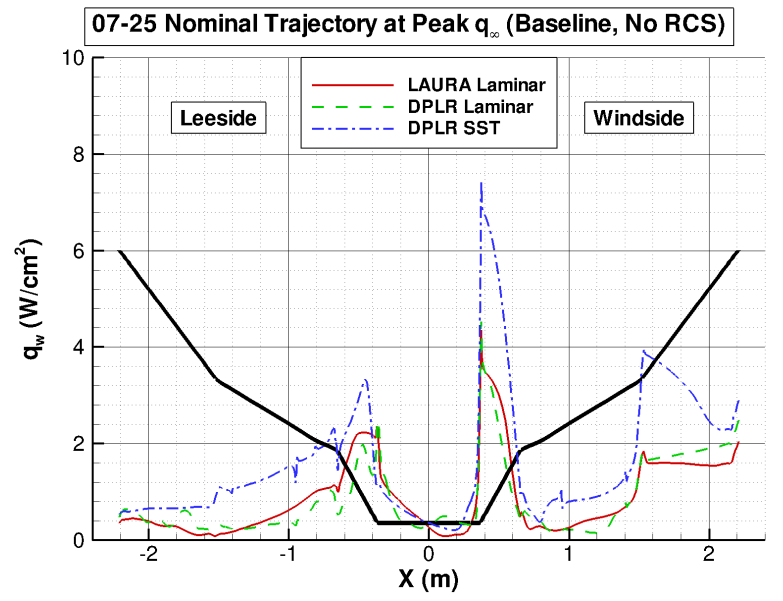

(a) Heat Flux at Peak Dynamic Pressure

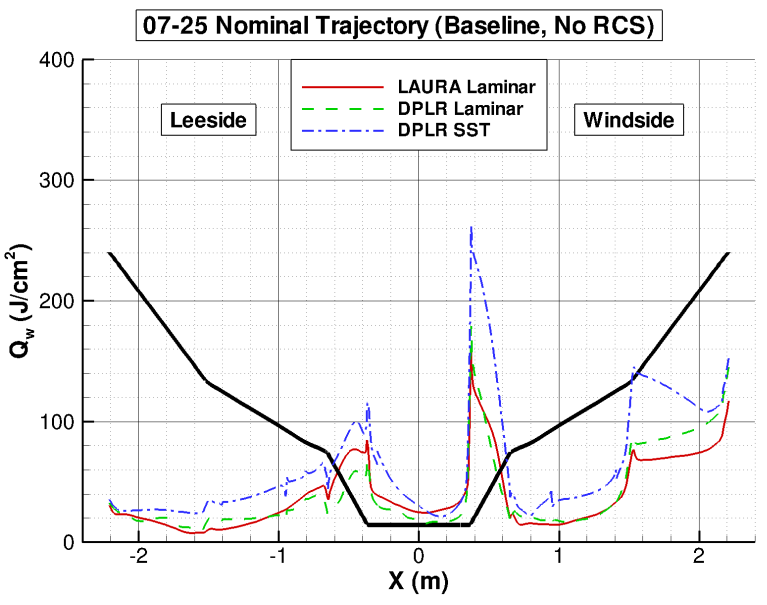

(b) Total Heat Load

Figure 6. LAURA and DPLR Solutions on the 07-25 Trajectory (No Uncertainties) 


\section{RCS Thruster Plume Effects}

Several CFD solutions were generated to better understand the interference effects of MSL's RCS thruster plumes $^{17}$ on both the capsule aerodynamics and aerothermal environments. Each nozzle of interest was modeled from fixed chamber conditions, generating a supersonic plume that intercepted the external flowfield, which itself is supersonic at the windside RCS location. The thrusters were modeled assuming steady-state plume development at maximum thrust (290 $\mathrm{N}$ for each nozzle) with non-reacting ammonia $\left(\mathrm{NH}_{3}\right)$ as the operating gas. No time-accurate simulations were attempted to model the initial nozzle startup and plume development. Both thrusters were assumed on at each RCS pair location to maximize plume interference.

Figure 7 shows LAURA and DPLR laminar heat flux with the yaw RCS thrusters on and significant thruster plume influence on the surface conditions. LAURA and DPLR predictions (using similar grids) match well in both heating distribution and magnitude. Plume-flowfield interactions cause heating augmentation near the nozzle exits and between the yaw thrusters. Windside thruster plume interaction is predicted to impinge the PCC sidewall and BIP (at 3 o'clock) with both codes. Neither the Heatshield/Backshell Seal nor the windside PCC Edge is influenced by the thruster firings. The entire side opposite the firing thrusters is essentially not affected by operation of the yaw jets. The high heating strip emanating from between adjacent nozzles is caused by a plume-plume interaction that is independent on the external flowfield. The heating patterns upstream of each nozzle and to the side of the windside fairing are due to plume-flowfield interactions that scale with freestream dynamic pressure. High heating encircling the nozzle exits is off scale and is partially a result of insufficient grid clustering and use of the radiative-equilibrium boundary condition. Previous RCS configurations resulted in even more plume interference effects and higher heating over a larger area, ${ }^{9}$ prompting the switch to SLA-561V on the backshell. In the final RCS arrangement shown here, higher heating near the thruster fairings will be of short duration and will not require more TPS than those areas with attached flow.

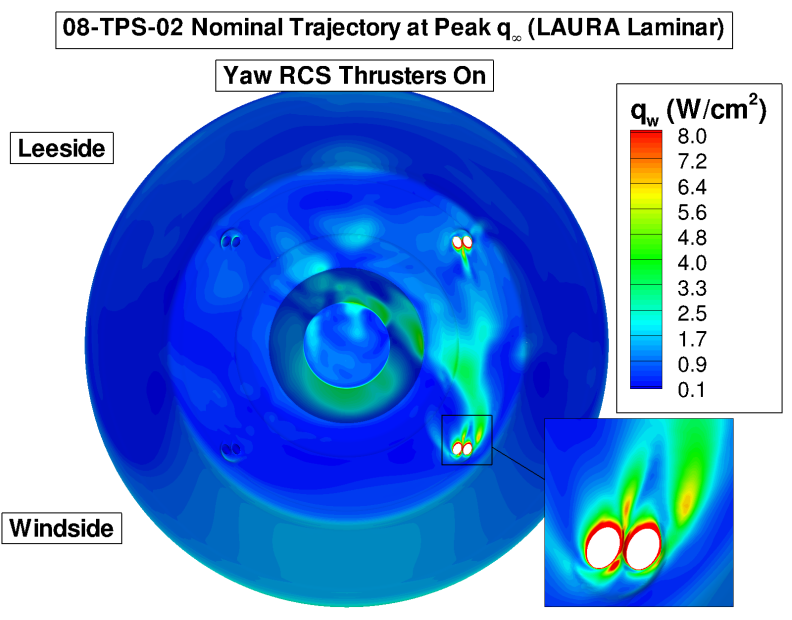

(a) LAURA

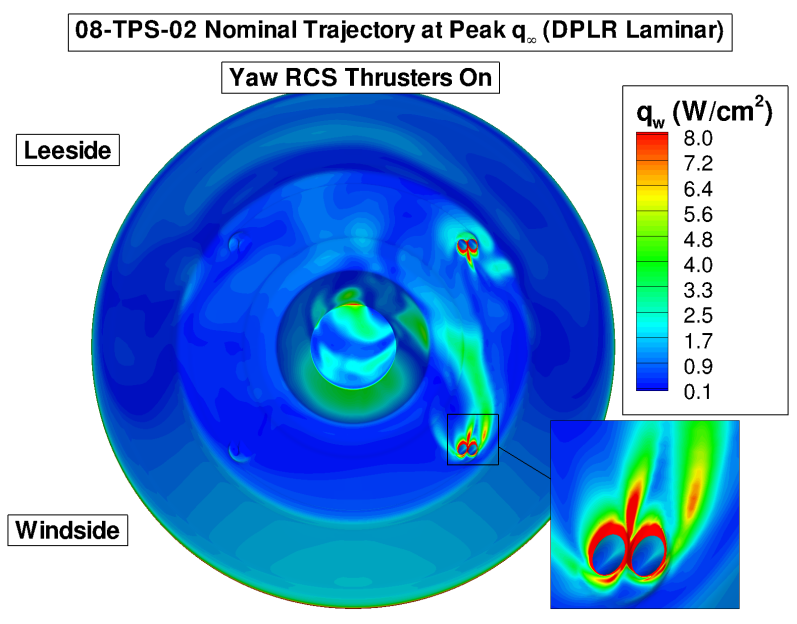

(b) DPLR

Figure 7. Yaw RCS Thruster Effects on Heat Flux at Peak Dynamic Pressure on the 08-TPS-02 Trajectory (No Uncertainties)

Based on the results in Figure 7, only the BIP aerothermodynamic design environments include the effects of yaw RCS thruster firings. The locally high heating on the leeside PCC edge is believed to be a transient feature spatially and temporally. The flow impingement on the PCC sidewall (3 o'clock) causes heat fluxes that are similar to the windside PCC Edge location, but the sidewall total heat load is lower because the RCS-off environments are more benign. Similarly, the heating near the RCS fairing is expected to be short duration and will not result in a total heat that is larger than the windside Heatshield/Backshell Seal location. Thus, the largest required SLA-561V thickness is located at the Heatshield/Backshell Seal. 


\section{Antenna Radome Environments}

The antenna radomes on the PCC lid required special calculations to define the environments and derive the minimum Acusil II thickness for mass savings and communications purposes. ${ }^{6}$ A computational grid that included the radomes was modeled using both LAURA and DPLR without RCS thruster influence. Figure 8 shows a code comparison of heat flux at the peak dynamic pressure time on a previous trajectory (06-05) similar to the current design trajectories. As expected, the protruding radomes cause local hot spots that exceed in magnitude the heating on the windside PCC Edge. Both codes were run in steady-state mode and had mixed success establishing a converged solution on the radomes. Figure 8 includes mirrored results for both LAURA and DPLR at two different times along the solution histories. Both codes were able to reach a steady-state heat flux on the PLGA radomes, but the LAURA magnitudes are $50 \%$ higher. Neither code was able to establish a fixed heat flux distribution on the TLGA radome. This result is not surprising given that both radomes are in a separated flowfield (Figure 5). The maximum heating on the PLGA radomes from DPLR is similar to the maximum LAURA TLGA heating. Conversely, the DPLR maximum TLGA heating is equal to the maximum LAURA heating on the PLGA. Given the difficulty in interpreting the results, the decision was made to simply use the maximum heat flux (about $7 \mathrm{~W} / \mathrm{cm}^{2}$, or 1.75 times the PCC Edge) between either code or radome location and apply those conditions to both locations. Thus, the radome design conditions were generated simply by multiplying the PCC Edge heating by 1.75 over the entire heat pulse. Similarly, in an effort to reduce TPS mass, the PCC Lid heat pulse was generated by multiplying the PCC Edge conditions by 0.5 to reflect the milder environments shown in Figure 8 . The lid is ejected during the parachute deployment event and must not re-contact the canopy, an event whose likelihood is reduced with a low mass lid.

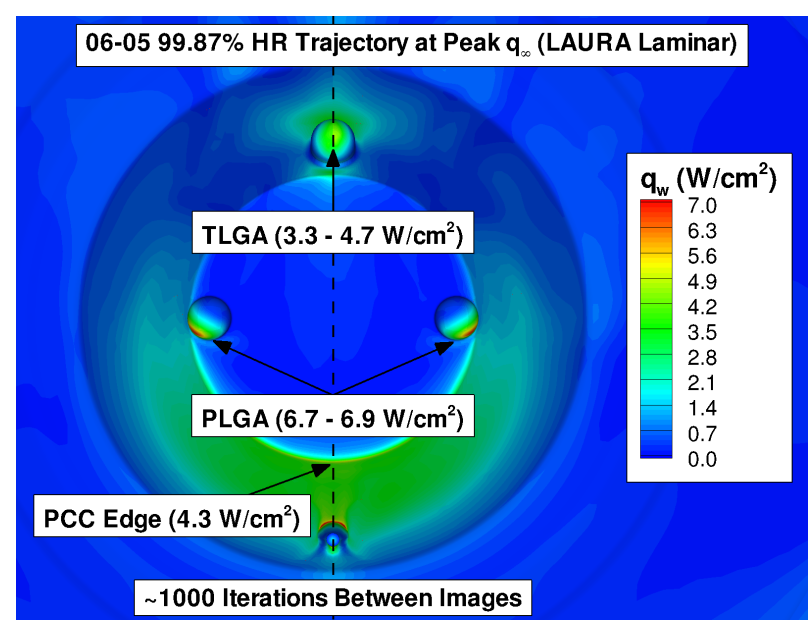

(a) LAURA

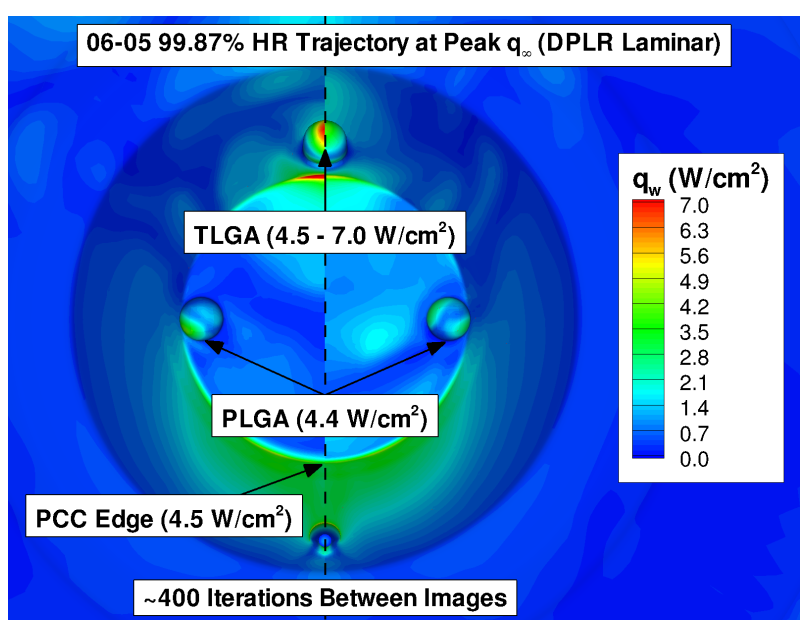

(b) DPLR

Figure 8. Antenna Radome Heat Flux at Peak Dynamic Pressure (No Uncertainties) 


\section{E. Design Environments}

The MSL heatshield aerothermodynamic design process ${ }^{7}$ includes a detailed estimate of biases and uncertainties that are added to the baseline CFD environments. The same analysis was not done here because of the large inherent uncertainties in afterbody flowfield prediction. Also, the backshell SLA-561V material is capable of much worse environments than MSL will experience and did not require more rigorous uncertainty quantification. The decision proposed by the AWG and accepted by the MSL project was to simply use a $200 \%$ uncertainty on laminar backshell, BIP, and PCC heat pulses (with or without RCS effects):

$$
q_{\text {Design }}=q_{L A U R A}+200 \%
$$

This uncertainty covers turbulence, angle-of-attack and trajectory dispersions, and CFD code discrepancies.

Table 3 summarizes the peak design environments at critical locations, regardless of when they occur. Peak heat flux, shear stress, and pressure values correspond to the steep 08-TPS-02 trajectory. Design total heat load corresponds to the shallow 08-TPS-01a trajectory. The mechanical loads (shear stress and pressure) are shown for completeness, but their low magnitudes are well within SLA-561V and Acusil II capabilities. Neither the SLA-561V nor the Acusil II will recess in flight, ${ }^{6}$ but rather will act as insulators. At the Heatshield/Backshell Seal location, the design values are $6.3 \mathrm{~W} / \mathrm{cm}^{2}$ for heat flux and $377 \mathrm{~J} / \mathrm{cm}^{2}$ for total heat load. The conditions at the Backshell Hip are less severe $\left(5.2 \mathrm{~W} / \mathrm{cm}^{2}\right.$ and $\left.245 \mathrm{~J} / \mathrm{cm}^{2}\right)$. As a comparison, the Pathfinder SLA-561V heatshield ${ }^{13}(0.75 \mathrm{in})$ survived much more severe heating environments ${ }^{28}$ $\left(118 \mathrm{~W} / \mathrm{cm}^{2}\right.$ and $\left.3800 \mathrm{~J} / \mathrm{cm}^{2}\right)$.

Only the BIP TPS thickness is influenced by RCS thruster firings. The total heat load was calculated assuming a continuous 8 second yaw thruster firing centered at peak dynamic pressure. This time interval was chosen to cover the maximum total on time for any thruster in six degree-of-freedom Monte-Carlo trajectory simulations. The resulting design conditions are $7 \mathrm{~W} / \mathrm{cm}^{2}$ for heat flux and $174 \mathrm{~J} / \mathrm{cm}^{2}$ for total heat load. Multiple PCC environments were needed to tailor the Acusil II thickness for mass savings and to facilitate antenna communications. ${ }^{6}$ The windside PCC Edge design conditions $\left(13 \mathrm{~W} / \mathrm{cm}^{2}\right.$ and $\left.499 \mathrm{~J} / \mathrm{cm}^{2}\right)$ are more severe than those at the Heatshield/Backshell Seal because of shear layer impingement discussed previously. The PCC Lid heating was scaled to $50 \%$ of the PCC Edge conditions based on CFD results without RCS thruster effects included. Similarly, the TLGA/PLGA radome design heating $\left(23 \mathrm{~W} / \mathrm{cm}^{2}\right.$ and $\left.873 \mathrm{~J} / \mathrm{cm}^{2}\right)$ was estimated by applying a bump factor of 1.75 to the PCC Edge conditions.

Table 3. Backshell/BIP/PCC Design Environments

\begin{tabular}{c|c|c|c|c} 
Location & Peak $q_{w}\left(\mathrm{~W} / \mathrm{cm}^{2}\right)$ & Peak $\tau_{w}(\mathrm{~Pa})$ & Peak $p_{w}(\mathrm{~atm})$ & $Q_{w}\left(\mathrm{~J} / \mathrm{cm}^{2}\right)$ \\
\hline \hline Heatshield/Backshell Seal & 6.3 & 36 & 0.005 & 377 \\
Backshell Hip & 5.2 & 28 & 0.009 & 245 \\
BIP (Inc. RCS Thruster Effects) & 7 & 23 & 0.005 & 174 \\
PCC Edge & 13 & 93 & 0.013 & 499 \\
PCC Lid (Scaled) & 6.5 & 46 & 0.006 & 250 \\
TLGA/PLGA Radomes (Scaled) & 23 & 162 & 0.019 & 873
\end{tabular}

Figure 9 shows the 08-TPS-01a time-dependent design conditions at critical TPS sizing locations. The heat loads from these curves require the thickest TPS. Time histories like those shown were provided for TPS modeling to verify thermal performance for SLA-561V (0.5 in) and determine minimum required Acusil II thicknesses. At the Heatshield/Backshell Seal location, 0.32 in of SLA-561V is required to maintain an acceptable bondline temperature during entry. ${ }^{6}$ The additional 0.18 in available is considered insurance against potential risks in the predicted aerothermodynamics and TPS material response. The TLGA and PLGA radomes require the most Acusil II (0.98 in) due to the heating augmentation discussed previously. Analysis has not been completed for the new 2011 launch date. Initial trajectory analysis shows that the change in launch date will result in an increased atmospheric entry velocity, which could result in higher heating on the backshell and PCC. 


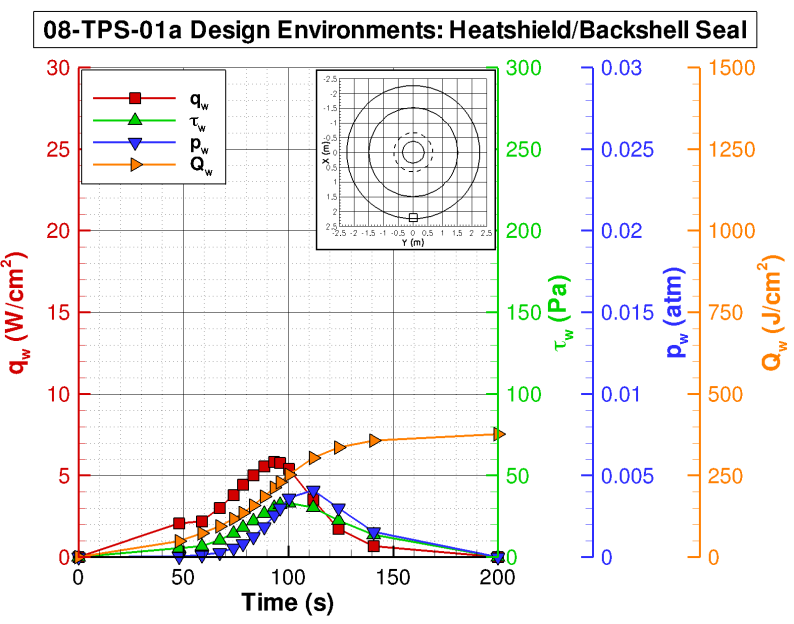

(a) Heatshield/Backshell Seal

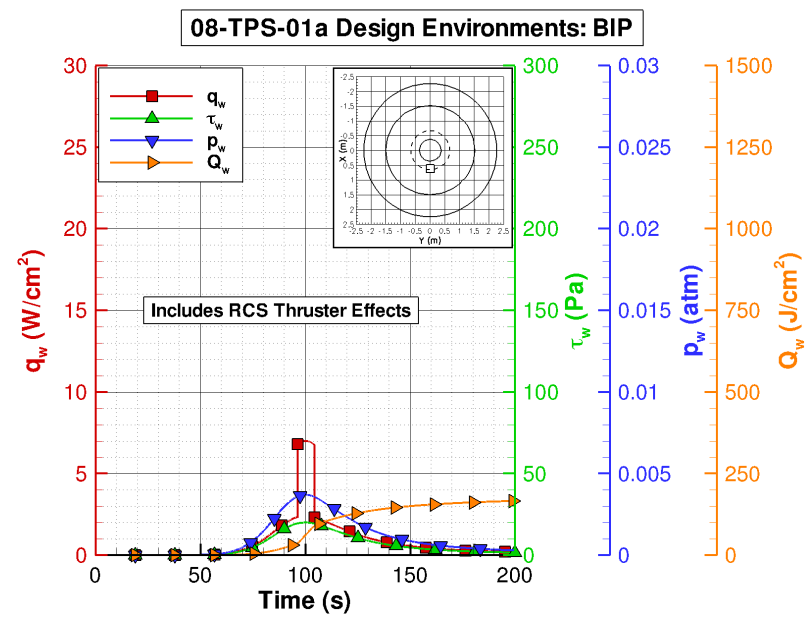

(c) BIP (Includes RCS Thruster Effects)

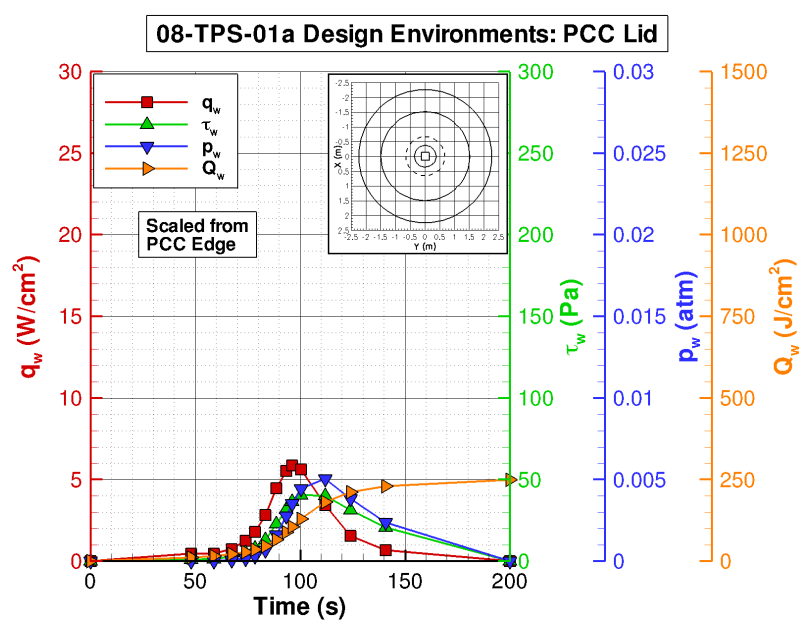

(e) PCC Lid (Scaled from PCC Edge)

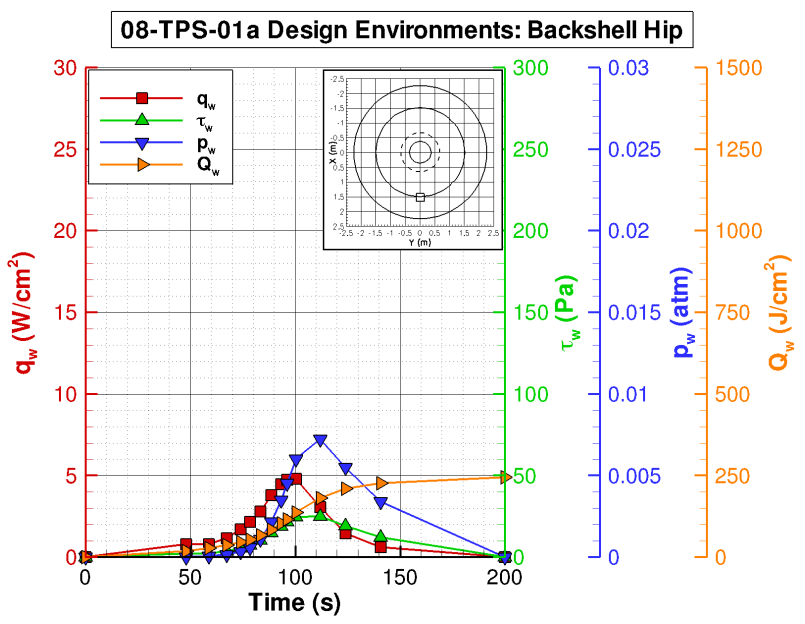

(b) Backshell Hip

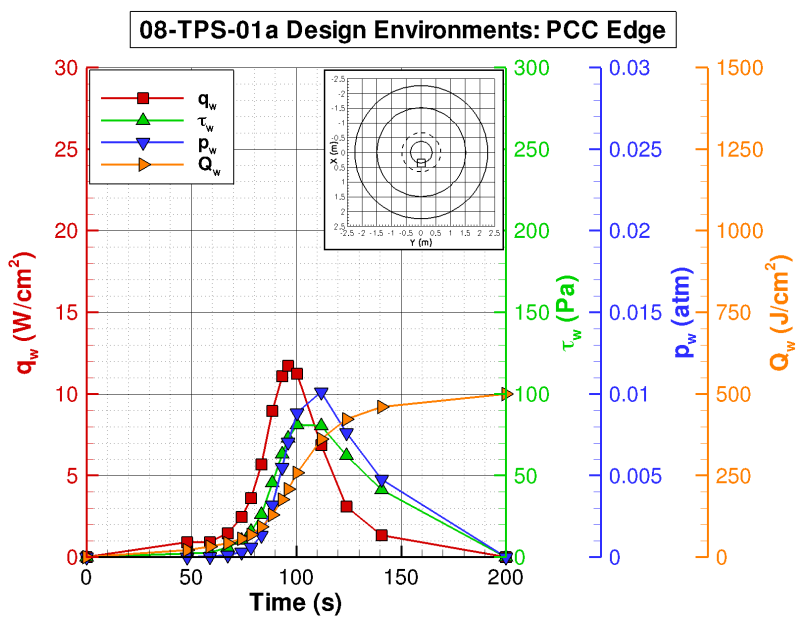

(d) PCC Edge

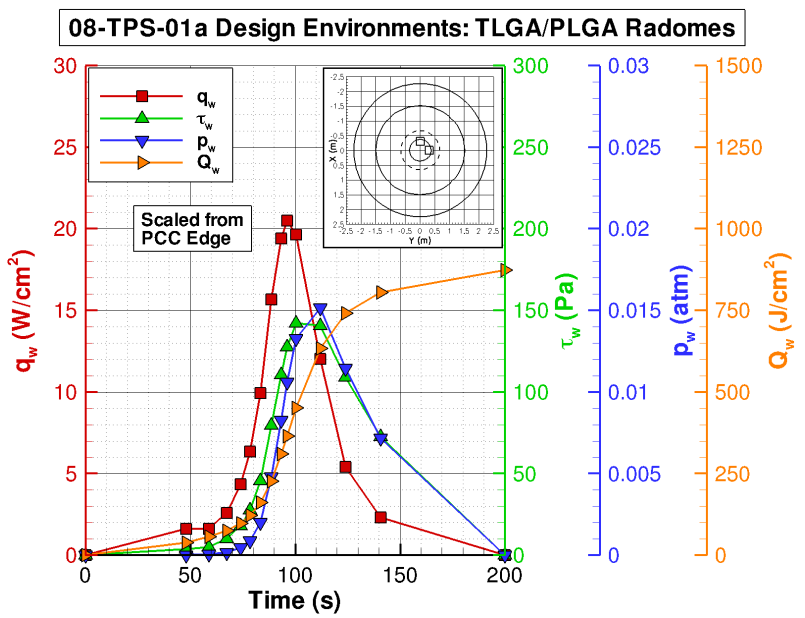

(f) TLGA/PLGA Radomes (Scaled from PCC Edge)

Figure 9. 08-TPS-01a Design Environments vs. Time 


\section{Summary and Conclusions}

Aerothermodynamic design conditions (heat flux, shear stress, pressure, and total heat load) were derived for the Mars Science Laboratory capsule backshell and parachute cover for entry following the original 2009 launch. Navier-Stokes flowfield solutions obtained on steep and shallow design trajectories formed the basis of the environments. Chemical and thermal non-equilibrium models were used to simulate the hypersonic and high-temperature conditions that will envelope the entry capsule during Mars atmospheric entry. CFD code discrepancies for flight environments predictions were within normal uncertainties. Reaction control thruster plumes were modeled computationally and are predicted to produce short duration heat flux augmentation near the thruster fairings on the backshell and around the parachute dome. However, the RCS-influenced heating is only predicted to increase required TPS thickness at the interface between the backshell and parachute cone. Other areas affected by the thruster plumes experience heating bumps of short duration at locations where the thruster-off conditions are relatively mild. The design environments were taken to be the maximum values from either the steep (maximum heat flux, shear stress, and pressure) or shallow (maximum total heat load) design trajectory. The design conditions at the Heatshield/Backshell Seal are $197 \mathrm{~W} / \mathrm{cm}^{2}$ for heat flux and $377 \mathrm{~J} / \mathrm{cm}^{2}$ for total heat load. More severe conditions are predicted at the leading edge of the parachute cone due to shear layer impingement $\left(13 \mathrm{~W} / \mathrm{cm}^{2}\right.$ and $\left.499 \mathrm{~J} / \mathrm{cm}^{2}\right)$. A heating bump factor of 1.75 was used to generate design conditions for two antenna radomes on the top of the parachute cone, resulting in the highest heating $\left(23 \mathrm{~W} / \mathrm{cm}^{2}\right.$ and $\left.873 \mathrm{~J} / \mathrm{cm}^{2}\right)$ of any afterbody location. Further analyses will be conducted to determine the effects of the 2011 launch date on aerothermodynamic environments and TPS performance.

\section{Acknowledgments}

The authors wish to thank the members of the MSL Aeroheating Working Group from NASA Langley and Ames Research Centers, NASA Jet Propulsion Laboratory, and Lockheed Martin Astronautics for their valuable contributions to the MSL aerothermodynamics analysis and thermal protection system design. Thanks also to Victor Lessard at NASA Langley Research Center for generating computational grids used for the LAURA flowfield calculations.

\section{References}

\footnotetext{
${ }^{1}$ Steltzner, A., et al, "Mars Science Laboratory Entry, Descent and Landing System," IEEE Paper 2006-1307, IEEE Aerospace Conference, Big Sky, Montana, March 2006.

${ }^{2}$ Anonymous, "Entry Data Analysis for Viking Landers 1 and 2 Final Report," TN-3770218 (also NASA CR-159388), Martin Marietta Corp., November, 1976.

${ }^{3}$ Braun, R. D., Powell, R. W., Engelund, W. C., Gnoffo, P. A., Weilmuenster, K. J., and Mitcheltree, R. A., "Mars Pathfinder Six-Degree-of-Freedom Entry Analysis," Journal of Spacecraft and Rockets, Vol. 32, No. 6, November-December, 1995, pp. 670-676.

${ }^{4}$ Desai, P., Schoenenberger, M., and Cheatwood, F. M., "Mars Exploration Rover Six-Degree-of-Freedom Entry Trajectory Analysis," Journal of Spacecraft and Rockets, Vol. 43, No. 5, September-October, 2006, pp. 1019-1025.

${ }^{5}$ Desai, P. N., Prince, J. L., Queen, E. M., Cruz, J. R., and Grover, M. R., "Entry, Descent, and Landing Performance of the Mars Phoenix Lander," AIAA Paper 2008-7346, AIAA Atmospheric Flight Mechanics Conference, Honolulu, Hawaii, August, 2008.

${ }^{6}$ Wright, M., Beck, R., Edquist, K., Driver, D., Sepka, S., and Slimko, E., "Sizing and Margins Assessment of the Mars Science Laboratory Aeroshell Thermal Protection System," AIAA Paper 2009-4231, AIAA Thermophysics Conference, San Antonio, Texas, June 2009.

${ }^{7}$ Edquist, K. T., Dyakonov, A. A., Wright, M. J., and Tang, C.-Y., "Aerothermodynamic Design of the Mars Science Laboratory Heatshield," AIAA Paper 2009-4075, AIAA Thermophysics Conference, San Antonio, Texas, June 2009.

${ }^{8}$ Edquist, K. T., Hollis, B. R., Dyakonov, A. A., Laub, B., Wright, M. J., Rivellini, T. P., Slimko, E. M., and Willcockson, W. H., "Mars Science Laboratory Entry Capsule Aerothermodynamics and Thermal Protection System," IEEEAC Paper 1423, IEEE Aerospace Conference, Big Sky, Montana, March 2007.

${ }^{9}$ Edquist, K. T., Dyakonov, A. A., Wright, M. J., and Tang, C.-Y., "Aerothermodynamic Environments Definition for the Mars Science Laboratory Entry Capsule," AIAA Paper 2007-1206, AIAA Aerospace Sciences Meeting and Exhibit, Reno, Nevada, January 2007.

${ }^{10}$ Hollis, B. R. and Collier, A. S., "Turbulent Aeroheating Testing of Mars Science Laboratory Entry Vehicle in Perfect-Gas Nitrogen," AIAA Paper 2007-1208, AIAA Aerospace Sciences Meeting and Exhibit, Reno, Nevada, January 2007.

${ }^{11}$ Liechty, D. S. and Hollis, B. R., "Mars Science Laboratory Experimental Aerothermodynamics with Effects of Cavities and Control Surfaces," Journal of Spacecraft and Rockets, Vol. 43, No. 2, March-April 2006, pp. 340-353.
} 
${ }^{12}$ Wright, M. J., Olejniczak, J., Brown, J. L., Hornung, H. G., and Edquist, K. T., Computational Modeling of T5 Laminar and Turbulent Heating Data on Blunt Cones, Part 2: Mars Applications," AIAA Paper 2005-0177, AIAA Aerospace Sciences Meeting and Exhibit, Reno, Nevada, January 2005.

${ }^{13}$ Willcockson, W. H., "Mars Pathfinder Heatshield Design and Flight Experience," Journal of Spacecraft and Rockets, Vol. 36, No. 3, May-June 1999.

${ }^{14}$ Beck, R., Driver, D., Wright, M., Laub, B., Slimko, E., and Edquist, K., "Development of the Mars Science Laboratory Heatshield Thermal Protection System," AIAA Paper 2009-4229, AIAA Thermophysics Conference, San Antonio, Texas, June 2009.

${ }^{15}$ Tran, H., Johnson, C. E., Rasky, D. J., Hui, F. C., Hsu, M.-T., Chen, T., Chen, Y.-K., Paragas, D., and Kobayashi, L., "Phenolic Impregnated Carbon Ablators (PICA) as Thermal Protection Systems for Discovery Missions," NASA TM-110440, April 1997.

${ }^{16}$ Schoenenberger, M., Dyakonov, A., Buning, Scallion, W., and Van Norman, J., "Aerodynamic Challenges for the Mars Science Laboratory Entry Descent and Landing," AIAA Paper 2009-3914, AIAA Thermophysics Conference, San Antonio, Texas, June 2009.

${ }^{17}$ Dyakonov, A., Schoenenberger, M., Scallion, W., Van Norman, J., Novak, L., and Tang, C., "Aerodynamic Interference Due to MSL Reaction Control System," AIAA Paper 2009-3915, AIAA Thermophysics Conference, San Antonio, Texas, June 2009.

${ }^{18}$ Dyakonov, A. A., Glass, C. E., and Desai, P. N., "Analysis of Effectiveness of Phoenix Entry Reaction Control System," AIAA Paper 2008-7220, AIAA Atmospheric Flight Mechanics Conference, Honolulu, Hawaii, August 2008.

${ }^{19}$ Wright, M. J., Edquist, K. T., Hollis, B. R., Olejniczak, J., and Venkatapathy, E., "Status of Aerothermal Modeling for Current and Future Mars Exploration Missions," IEEEAC Paper 1428, IEEE Aerospace Conference, Big Sky, Montana, March 2006.

${ }^{20}$ Cheatwood, F. M. and Gnoffo, P. A., "Users Manual for the Langley Aerothermodynamic Upwind Algorithm (LAURA)," NASA TM-4674, April 1996.

${ }^{21}$ Wright, M. J., Candler, G. V., and Bose, D., "Data-Parallel Line Relaxation Method for the Navier-Stokes Equations," AIA A Journal, Vol. 36, No. 9, 1998, pp. 1603-1609.

${ }^{22}$ Gnoffo, P. A., Braun, R. D., Weilmuenster, K. J., Mitcheltree, R. A., Engelund, W. C., and Powell, R. W., "Prediction and Validation of Mars Pathfinder Hypersonic Aerodynamic Data Base," Journal of Spacecraft and Rockets, Vol. 36, No. 3, May-June 1999.

${ }^{23}$ McDaniel, R. D., Wright, M. J., and Songer, J. T., "Aeroheating Predictions for Phoenix Entry Vehicle," AIAA Paper 2008-1279, AIAA Aerospace Sciences Meeting and Exhibit, Reno, Nevada, January 2008.

${ }^{24}$ Cheatwood, F. M., Merski, Jr., N. R., Riley, C. J., and Mitcheltree, R. M., "Aerothermodynamic Environment Definition for the Genesis Sample Return Capsule," AIAA 2001-2889, AIAA Thermophysics Conference, Anaheim, California, June 2001.

${ }^{25}$ Tang, C. and Wright, M. J., "Analysis of the Forebody Aeroheating Environment During Genesis Sample Return Capsule Reentry," AIAA Paper 2007-1207, AIAA Aerospace Sciences Meeting and Exhibit, Reno, Nevada, January 2007.

${ }^{26}$ Menter, F. R., "Two Equation Eddy-Viscosity Turbulence Models for Engineering Applications," AIAA Journal, Vol. 32, No. 8, 1994, pp. 1598-1605.

${ }^{27}$ Schmitt, D. A., "Base Heating on an Aerobraking Orbital Transfer Vehicle," AIAA Paper 83-0408, AIAA Aerospace Sciences Meeting and Exhibit, Reno, Nevada, January 1983.

${ }^{28}$ Milos, F. S., Chen, Y.-K., Congdon, W. M., and Thornton, J. M., "Mars Pathfinder Entry Temperature Data, Aerothermal Heating, and Heatshield Material Response," Journal of Spacecraft and Rockets, Vol. 36, No. 3, May-June 1999.

${ }^{29}$ Edquist, K. T., Wright, M. J., and Allen, G. A., "Viking Afterbody Heating Computations and Comparisons to Flight Data," AIAA Paper 2006-0386, AIAA Aerospace Sciences Meeting and Exhibit, Reno, Nevada, January 2006. 